\title{
Methodological tools to study species of the genus Burkholderia
}

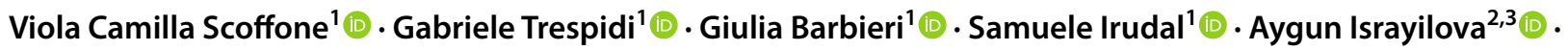 \\ Silvia Buroni ${ }^{1}$ (1)
}

Received: 13 September 2021 / Revised: 25 October 2021 / Accepted: 26 October 2021 / Published online: 10 November 2021

(c) The Author(s), under exclusive licence to Springer-Verlag GmbH Germany, part of Springer Nature 2021

\begin{abstract}
Bacteria belonging to the Burkholderia genus are extremely versatile and diverse. They can be environmental isolates, opportunistic pathogens in cystic fibrosis, immunocompromised or chronic granulomatous disease patients, or cause disease in healthy people (e.g., Burkholderia pseudomallei) or animals (as in the case of Burkholderia mallei). Since the genus was separated from the Pseudomonas one in the 1990s, the methodological tools to study and characterize these bacteria are evolving fast. Here we reviewed the techniques used in the last few years to update the taxonomy of the genus, to study gene functions and regulations, to deepen the knowledge on the drug resistance which characterizes these bacteria, and to elucidate their mechanisms to establish infections. The availability of these tools significantly impacts the quality of research on Burkholderia and the choice of the most appropriated is fundamental for a precise characterization of the species of interest.
\end{abstract}

\section{Key points}

- Updated techniques to study the genus Burkholderia were reviewed.

- Taxonomy, genomics, assays, and animal models were described.

- A comprehensive overview on recent advances in Burkholderia studies was made.

Keywords Burkholderia $\cdot$ Taxonomy $\cdot$ Genomics $\cdot$ Quorum sensing $\cdot$ Animal models

\section{Introduction}

The genus Burkholderia (phylum Proteobacteria, class $\beta$-Proteobacteria, order Burkholderiales, family Burkholderiaceae) was differentiated by the Pseudomonas one in 1992 based both on phenotypic characteristics as well as on 16S rRNA sequences, cellular lipid and fatty acid composition (Yabuuchi et al. 1992). Today, it comprises more than 120 species which live in different environments and are also able to colonize plants and animals, both in a beneficial and a pathogenic manner. Indeed, species able to

Silvia Buroni

silvia.buroni@unipv.it

1 Department of Biology and Biotechnology, University of Pavia, Pavia, Italy

2 Department of Molecular Biology and Biotechnology, Baku State University, Baku, Azerbaijan

3 Scientific Research Institute of Geotechnological Problems of Oil, Gas, and Chemistry, Azerbaijan State Oil and Industry University, Baku, Azerbaijan promote plant growth and isolated from natural environments have been recently grouped in the genus Paraburkholderia (Vio et al. 2020). Another positive aspect of these bacteria is their ability to degrade a wide variety of pollutants, thus serving as bioremediation agents. On the other hand, the genus encompasses plant and animal pathogens, which can be host-specific or not. As an example, Burkholderia cepacia, which was firstly described as responsible for onion soft rot (Burkholder 1950), is also an opportunistic pathogen for cystic fibrosis and chronic granulomatous disease patients since it can cause a fatal pneumonia known as "the cepacia syndrome." It belongs to the Burkholderia cepacia complex (Bcc) that, together with Burkholderia mallei (the etiological agent of glanders) and Burkholderia pseudomallei (which causes melioidosis) represent the most clinically relevant species.

This mini-review is a comprehensive summary of the most recent advances in the setup of methods useful to study not only the classification but also the main features of the Burkholderia genus, including the genome and the drug resistance.

Since the taxonomy of Burkholderia has changed very much in the last years, this mini-review will start with a 
paragraph describing the old and more recent techniques used for the classification of these bacteria.

Another peculiarity of Burkholderia bacteria is their large genome, typically composed of two or three chromosomes, containing more than 5,000 genes (www.burkholderia.com). An important tool to understand their function is gene deletion: here we review some methods developed to allow gene deletion and silencing.

Unfortunately, Burkholderia pathogenic species share another common feature: drug resistance. Besides the "classical" mutations in genes encoding drug targets and the production of antibiotic modifying enzymes, the poor membrane permeability, the presence of efflux pumps, as well as the ability to form biofilm have been reported as drug resistance mediators in these bacteria. Since this renders the treatment of infections particularly challenging, here we will describe different methodologies which can contribute to find therapies alternative to the existing ones. These include the use of transposon libraries as a tool for drug discovery, the implementation of different types of assays for the characterization of quorum sensing, a process playing a central role in gene regulation and representing a key target for the development of antivirulence compounds, and the employment of animal models useful for the elucidation of the establishment of infections.

\section{Traditional and new techniques to describe the taxonomy of the Burkholderia genus}

The accurate identification of bacterial species belonging to the Burkholderia genus is very important, as they are considered opportunistic pathogens that cause life-threatening infections to immunocompromised patients. Moreover, the increasing resistance of these bacteria to many antibiotics implies the need for fast and reliable identification methods (Israyilova et al. 2016; Trespidi et al. 2020). The greatest obstacle in the correct identification of these pathogens is the high similarity among these species (Furlan et al. 2019; Jin et al. 2020; Martinucci et al. 2016; Wang et al. 2020). Different methods can be used for the identification of these bacteria (Table 1), such as the sequencing of $16 \mathrm{~S} r R N A$, $23 S$ rRNA, recA, hisA, rpsU genes, and matrix-assisted laser desorption/ionization time-of-flight mass spectrometry (MALDI-TOF MS) (Wong et al. 2020; Fergusson et al. 2020; Gassiep et al. 2019; Furlan et al. 2019; Haeckl et al. 2019; Frickmann et al., 2014).

The sequencing of the $16 S$ rRNA and 23S rRNA genes are extensively applied for bacterial identification in most laboratories. Despite studies have indicated that these methods can efficiently identify Burkholderia genus among other genera, with this method it is not possible to distinguish within the species (Furlan et al. 2019; Jin et al. 2020; Peeters et al. 2016). Jin et al. (2020) explored that $16 S$ rRNA gene has limited taxonomic resolution in the identification of Burkholderia cepacia complex $(\mathrm{Bcc})$ species, in line with the results from other reports (Furlan et al. 2019). By the modification of Selective Medium-design Algorithm Restricted by Two constraints (SMART) protocol, a selective isolation strategy for Burkholderia strains was developed. This new method is based on 16S rRNA and multiplex PCR sequencing for the genus level identification, with reports of $95 \%$ accuracy for bacterial samples (Haeckl et al., 2019).

The recA gene was considered another well-known molecular marker promising for accurate identification of Burkholderia species, but differentiation from non-Burkholderia species is tricky with this approach (Furlan et al. 2019; Wong et al. 2020; Depoorter et al. 2020).

hisA gene encodes a protein involved in histidine biosynthesis, which is used to distinguish species within the

Table 1 Methods used to describe the taxonomy of the Burkholderia genus

\begin{tabular}{|c|c|c|}
\hline Method & Accuracy & References \\
\hline $16 S r R N A$ and $23 S$ rRNA gene sequencing & No distinction within species & Furlan et al. 2019; Jin et al. 2020; Peeters et al. 2016 \\
\hline $\begin{array}{l}\text { Selective medium-design algorithm restricted by two } \\
\text { constraints }\end{array}$ & $95 \%$ & Haeckl et al., 2019 \\
\hline recA gene sequencing & $93.08-100 \%$ & $\begin{array}{l}\text { Furlan et al. 2019; Wong et al. 2020; Depoorter et al. } \\
2020\end{array}$ \\
\hline hisA gene sequencing & $91.76-100 \%$ & Jin et al. 2020 \\
\hline$r p s U$ gene sequencing & No distinction within species & Frickmann et al., 2014 \\
\hline Multilocus sequence typing/analysis (MLST/MLSA) & No distinction within species & Jin et al. 2020; Furlan et al. 2019 \\
\hline Raman spectroscopy (RS) & $90-100 \%$ & $\begin{array}{l}\text { Stöckel et al., 2015; Kloß et al. 2015; Moawad et al. } \\
2019\end{array}$ \\
\hline $\begin{array}{l}\text { Matrix-assisted laser desorption/ionization time-of- } \\
\text { flight mass spectrometry (MALDI-TOF MS) }\end{array}$ & $97-100 \%$ & $\begin{array}{l}\text { Fergusson et al. 2020; Wong et al. 2020; Depoorter et al. } \\
\text { 2020; Gassiep et al. 2019; Wattal et al. } 2017\end{array}$ \\
\hline $\begin{array}{l}\text { Liquid chromatography-mass spectrometry multiple } \\
\text { reaction monitoring (LC-MS/MS MRM) }\end{array}$ & $97-100 \%$ & Wang et al. 2020 \\
\hline
\end{tabular}


Burkholderia genus. It was reported that the accuracy of recA sequences ranged from 93.08 to $100 \%$ for $116 \mathrm{Bcc}$ isolates, while hisA sequences identity of 115 strains ranged between 91.76 and 100\% (Jin et al. 2020). However, phylogenetic trees relying on recA and hisA genes revealed better results than $16 S r R N A$, although some extent of confusion and discordance was detected in the recA and hisA phylogenies (Jin et al. 2020).

rps $U$ sequencing method allows identification of the Burkholderia genus, but another molecular procedure is required for the identification at the species level of identification (Frickmann et al., 2014). Multilocus sequence typing/analysis (MLST/MLSA) is based on the nucleotide sequences of the alleles in order to show similarities within strains belonging to different species and genera. Studies revealed that sequence typing (ST) is not well characterized yet because of the great genetic variation among Burkholderia species, so it is suggested to use other molecular techniques able to detect diversity among these species (Jin et al. 2020; Furlan et al. 2019).

Raman Spectroscopy (RS) is a modern technique which differentiates bacteria by combining the spectral information of samples with machine learning validated reference spectra. The technique relies on the unique molecular composition showed by bacteria owing different phenotypes, which leads to minimal but important differences in their corresponding Raman spectra. Indeed, RS determines vibrational modes of molecules which provide a structural fingerprint to identify the molecules themselves. Since RS efficiency is low, long measurement times are needed to reach high identification accuracies (Ho et al. 2019). RS is different from other applied tools-including low cost ones-performing high speed analyses and extensive range of information about the chemical composition and interaction between the biomolecules within the microbes are available (Stöckel et al. 2015; Kloß et al. 2015). Moawad et al. (2019) has used RS assay to identify B. mallei, B. pseudomallei, and other Burkholderia spp. strains: here samples were inactivated by heat instead of formaldehyde compared with the work from Stöckel et al. (2015). The accuracy of the tool is characterized by high sensitivities ( $\geq 95 \%$ ) for the identification of $B$. mallei, B. pseudomallei species and is in line with the report by Stöckel et al. (2015). The Burkholderia strains were properly identified with sensitivities that ranged between 90 and 100\% (Moawad et al. 2019).

Recent automated system MALDI-TOF MS (VITEK 2, VITEK MS, and Bruker Biotyper) emerged as sensitive, practical, rapid and inexpensive tools for bacterial identification in most clinical microbiology laboratories. The identification technique is based on spectral analysis of ribosomal and heat shock proteins of the bacterial cell (Fergusson et al. 2020; Wong et al. 2020; Depoorter et al. 2020; Gassiep et al. 2019; Wattal et al. 2017). It was reported that determination of Burkholderia bacteria by MALDI-TOF MS at the genus level was reliable and the accuracy ranged between 97 and $100 \%$ for all bacteria samples. At the species level, the correct identification rate ranged from 26 to $83 \%$ according to the MS system, whether or not the achieved spectrum of the isolate is matched to the reference spectra included in the database (De Dios et al. 2016; Wong et al. 2020; Gautam et al. 2017; Kenna et al. 2017). Studies have shown that no automated systems could accurately identify all Burkholderia samples at the species level with the current database versions (Wong et al. 2020). Taking into account these results, Wang et al. (2020) developed a gene-protein based approach using Liquid Chromatography-Mass Spectrometry Multiple Reaction Monitoring (LC-MS/MS MRM) to identify Bcc: 16 different peptides were used to construct an automated multiplex LC-MS/MS MRM assay. A drawback of this assay is that the operator plays the main role in the manual curation of the phylogenetic partitions (Wang et al. 2020). Fergusson et al. (2020) have recently created the main spectral reference library for the MALDI mass spectrometer (Bruker Biotyper) for Burkholderia strains and related genera. As no false result was detected at the genus level, the MALDI Biotyper tool can be used even when specific species are not present in the reference library (Fergusson et al. 2020). The large scale library for Burkholderiales is free for use. This library and other relevant data can be downloaded (https://doi.org/10.5061/dryad.pk0p2ngjx), making the property of MALDI mass spectrometer contingent on the size and quality of the reference library.

In summary, the taxonomy of the Burkholderia genus changed a lot especially in the last few years, when new techniques were developed to precisely discriminate among the various species. This led to divide the genus into Burkholderia sensu stricto and six new other genera: Paraburkholderia (Sawana et al. 2014), Caballeronia (Dobritsa and Samadpour, 2016), Robbsia (Lopes-Santos et al. 2017), Pararobbsia (Lin et al. 2020), Mycetohabitans, and Trinickia (Estrada-de Los Santos et al. 2018). As regarding the Bcc, an update has been recently reported by Jin et al. (2020).

\section{Understanding gene function: deletion techniques}

Genetic tools are essential to study molecular mechanisms involved in cellular processes. Burkholderia species are characterized by high levels of antibiotic resistance, high GC content and large genomes, all features that make the editing methods designed for Gram-negative bacteria inefficient for use in Burkholderia.

The commonly used methods for gene deletion in Burkholderia are based on disruption of the targeted genes with an antibiotic-resistance marker, through an 
a

Host genomic DNA
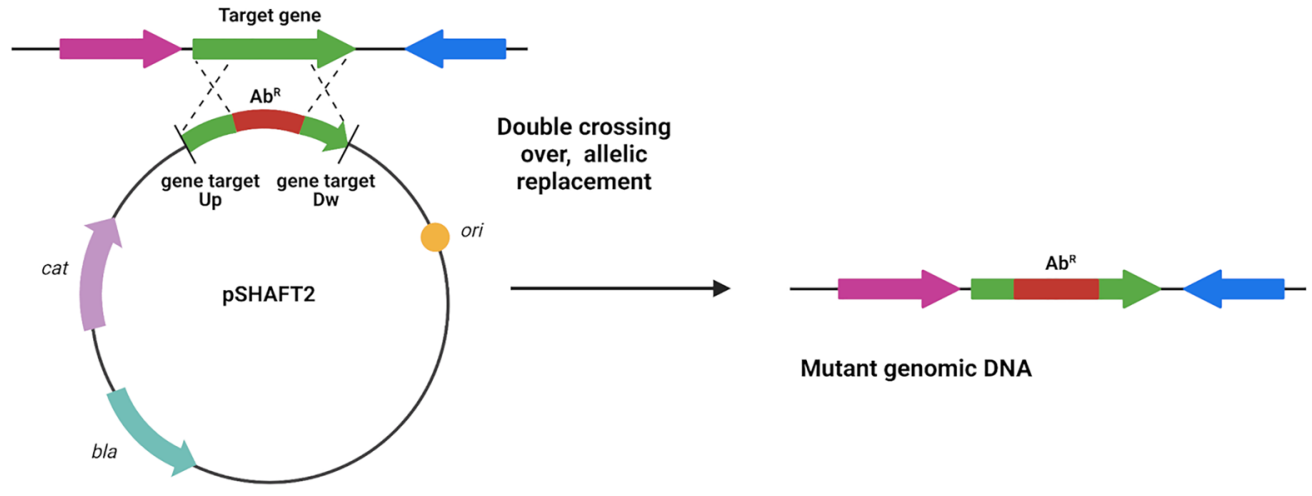

Mutant genomic DNA

b

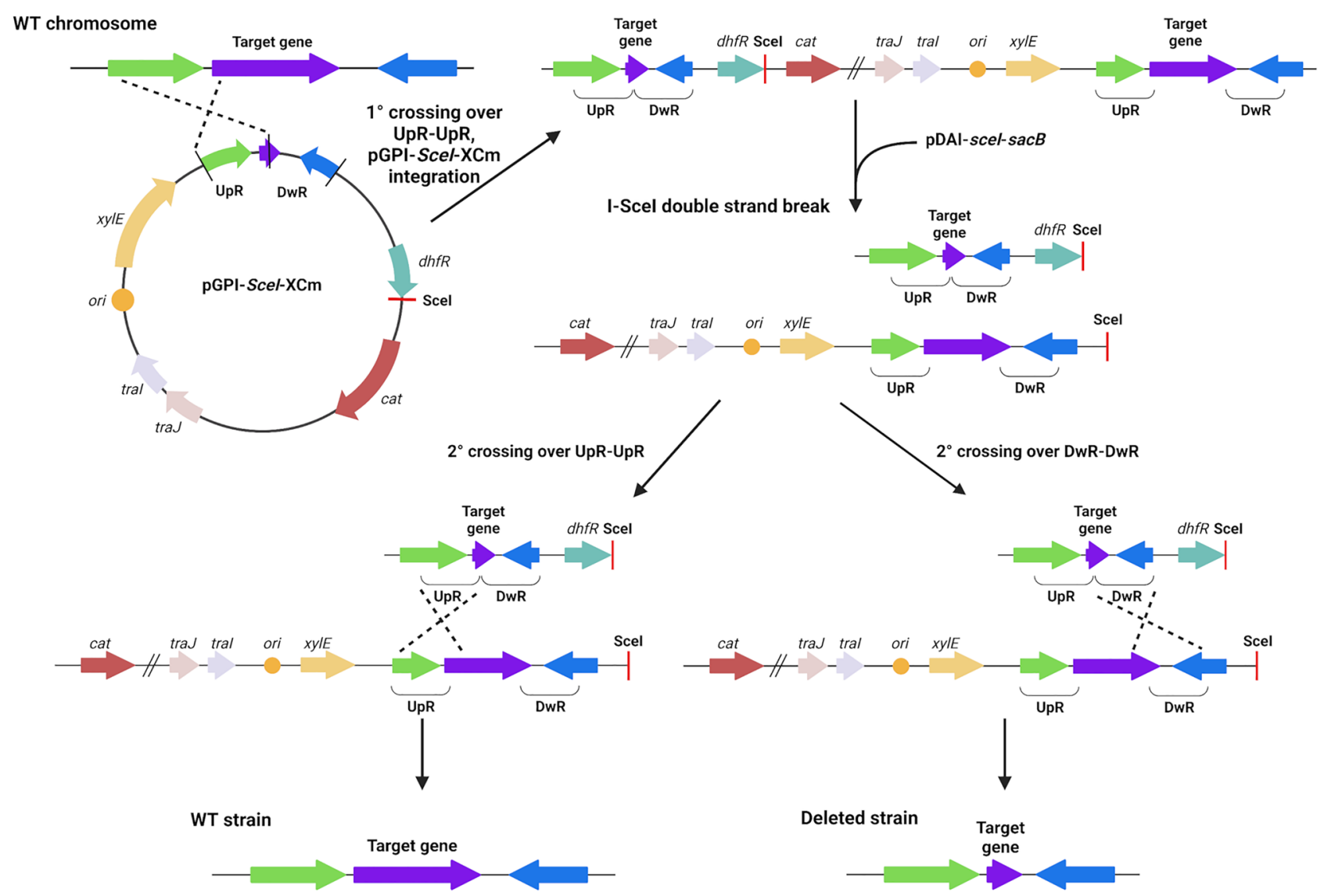

integrative vector or by allelic replacement of the target gene with an antibiotic resistance cassette. Nowadays, the most used method for gene inactivation is based on two recombination events near the target gene, so that no vector sequences (including antibiotic-resistance cassettes) remain on the chromosome of the mutant, thus allowing the creations of multiple deletions at a time. More recently other gene silencing mechanisms for Burkholderia were developed, based on recombineering or on CRISPR technology. 
४Fig. 1 Schematic diagram depicting the two gene deletion methods in Burkholderia: a gene replacement procedure described by Shastri et al. (2017). A fragment of DNA ( $\geq 1.0 \mathrm{~kb})$ containing the target gene (or gene fragment) is cloned into a pSHAFT vector and then disrupted by insertion of an antibiotic resistance cassette, ensuring there is at least $0.5 \mathrm{~kb}$ of homology between the cloned DNA target region and the chromosome on either side of the cassette. The pSHAFT-derived construct is transferred into bacteria, double crossover recombinants are selected based on their resistance to the antibiotic specified by the antibiotic resistance cassette, and either sensitivity to chloramphenicol; $\mathbf{b}$ the gene replacement procedure described by Flannagan et al. (2008). The suicide vector pGPI-SceI-XCm contains regions of homology flanking the target gene in purple (UpR, green and DwR, blue). The vector is transferred into bacteria by conjugation and integrated into the chromosome by the first homologous recombination event, resulting in trimethoprim and chloramphenicol resistant merodiploids. The pDAI-SceI-SacB is transferred into the merodiploid by conjugation. The I-SceI endonuclease expressed from the plasmid introduces a double-stranded DNA break at the I-SceI recognition site on the chromosome (in red). The DNA break stimulates the second homologous recombination event through the host DNA repair system. Depending on the location of the second recombination event, the resolution of the merodiploid state either restores the wild-type allele or generates the desired gene deletion. (Created with BioRender.com)

Gene deletion based on allelic replacement allows to replace the wild type gene with a selectable resistance marker, but the use of these techniques could be problematic if the host bacteria exhibit high intrinsic resistance to antibiotics. To improve this method, Shastri et al. (2017) constructed pSHAFT-derived suicide vectors for insertional inactivation, containing the chloramphenicol resistance $\left(\mathrm{Cm}^{\mathrm{R}}\right)$ (Fig. 1a), which allow the insertion of an antibiotic resistance cassette in the gene of interest through a double crossing over. These vectors were also improved after the substitution of the $\mathrm{Cm}^{\mathrm{R}}$ with the GFP that allows fluorogenic detection of recombinants in strains already harboring a $\mathrm{Cm}^{\mathrm{R}}$ (Fig. 1a) (Shastri et al. 2017). These inactivation methods were validated in B. cenocepacia and B. lata (Shastri et al. 2017).

On the other hand, the most elegant method to obtain an in-frame unmarked, marker-free, nonpolar recombination is the allelic replacement developed by Flannagan and co-workers (Flannagan et al. 2008; Hamad et al. 2010) (Fig. 1b). The regions flanking the target gene are cloned in a suicide vector called pGPI-SceI-XCm containing a SceI endonuclease recognition site (Fig. 1b). The vector is then mobilized into Burkholderia by triparental mating, and cointegrants are selected using trimethoprim and chloramphenicol. The plasmid pDAI-SceI-SacB, which carries the I-SceI endonuclease encoding gene, is mobilized into $B$. cenocepacia cointegrants. I-SceI produces a genomic strand break and another homologous recombination event allows bacteria to repair the break with a $50 \%$ chance of resulting in a gene deletion (Fig. 1b) (Flannagan et al. 2008; Hamad et al. 2010). The resolution of merodiploids is obtained by the excision of the integrated plasmid and the counterselection is based on tetracycline resistance and trimethoprim and chloramphenicol sensitivity.

This method was recently used to study the role of two tyrosine kinases (BCAM1331 and BceF) and of the low molecular weight protein tyrosine phosphatases BCAM0208, $\mathrm{BceD}$, and BCAL2200 in pathogenesis and physiology (Andrade et al. 2016). This technique is extremely useful also in gene regulation studies, such as the characterization of the small regulatory RNA ncS35 (Kiekens et al. 2018) and of the two DNA methyltransferases (BCAL3494 and BCAM0992) involved in biofilm formation, cell aggregation, and motility (Vandenbussche et al. 2020).

This mutagenesis strategy was modified to be used with many different species of the Bcc, such as the members of the B. cenocepacia IIIB Midwest clones (Abdu et al. 2018). The tetracycline resistance cassette of the pDAI-SceI-SacB was substituted with a trimethoprim marker and the suicide vector was modified with only the chloramphenicol resistance cassette (Abdu et al. 2018). The protocol was used to obtain a B. cenocepacia PC184 strain deleted in the lipooligosaccharide inner core biosynthesis (Abdu et al. 2018).

The same mechanism of deletion, based on homologous recombination, was used in $B$. thailandensis to demonstrate that the ATPase of the type VI secretion system (T6SS), $\mathrm{ClpV}$, has a T6SS-independent localization in the cell (Lennings et al. 2019). The $\Delta$ T6SS-5 B. thailandensis strain was obtained using the suicide vector pJRC115 (Lennings et al. 2019).

Moreover, this protocol was applied also in other Burkholderia species, such as B. pseudomallei and Burkholderia glumae. In $B$. pseudomallei, the in-frame deletion was obtained using the suicide vector pDM4 and mutants were obtained after growth on salt free LB containing 10\% glucose (Wagley et al. 2017). The deletion of the glidobactin synthesis gene $(g l b C)$ of $B$. pseudomallei showed its involvement in bacteria survival in murine macrophages (Wagley et al. 2017). To develop a live attenuated vaccine against B. pseudomallei, multiple B. pseudomallei MSHR668 deletion mutants were constructed using the $s a c B$-based vector pMo130, and exconjugants were selected on LB agar without $\mathrm{NaCl}$ and with $10 \%$ glucose with incubation at $25^{\circ} \mathrm{C}$ for four days (Amemiya et al. 2019). In B. glumae, the study of the core oligosaccharide and $\mathrm{O}$-antigen region was performed obtaining the deleted strains for waaC and wbiFGHI genes, using a suicide vector (Lee et al. 2019).

Another way to study gene expression and regulation in Burkholderia is based on the construction of conditional mutants, such as in the case of colistin resistance in B. thailandensis. A conditional mutant of arn operon was obtained with the insertion vector $\mathrm{pSC} 200$ that contains an inducible rhamnose promoter to regulate the expression of the operons (Panta and Doerrler 2021). 
Genetic manipulation (deletion, insertion, replacement, point mutation, multi-fragment assembly and direct cloning of large fragments) can be also obtained with recombineering systems. This is based on the phage-encoded homologous recombination systems $\operatorname{Red} \alpha / \operatorname{Red} \beta / \operatorname{Red} \gamma$ of the lamba phage Red operon or on the RecE/RecT from Rac prophage (Li et al., 2021). Recently, this method was applied to B. glumae and B. plantarii, using three Rac bacteriophage RecETlike operons of Burkholderia. These recombineering systems were introduced by inserting functional promoters to activate cryptic non-ribosomal peptides. This system has the advantage of utilizing shorter homology arms ( $\sim 50 \mathrm{bp})$ which can be included in synthetic oligonucleotides (Li et al., 2021).

Finally, Hogan et al. (2019) developed a CRISPR interference technology for gene silencing in $B$. cenocepacia, $B$. multivorans and $B$. thailandensis. The modulable expression was obtained by placing a dcas 9 from Streptococcus pyogenes under the control of a rhamnose inducible promoter (Hogan et al. 2019). This system was tested on the phenylacetic acid degradation operon (paaABCDE) and on $p h b C$ and $f i F$ genes, which were all successfully silenced (Hogan et al. 2019).

Another example of genetic manipulation in Burkholderia species is the deletion of the entire chromosome three in $B$. cenocepacia. The Bcc genome consists of three replicons that were considered chromosomes because they apparently carried essential genes and each of them carried at least one rRNA operon (Agnoli et al., 2012). However, during a transposon library mutagenesis study, Agnoli and coworker isolated B. cenocepacia $\mathrm{H} 111$ mutants attenuated in virulence that had lost chromosome three. Later, using a chromosome three mini-replicon to cure chromosome three from strains of Bcc species by plasmid incompatibility, they obtained nine Bcc strains without the chromosome three (Agnoli et al., 2012). This experiment demonstrated that the chromosome three carries virulence, secondary metabolites and other accessory functions in Bcc bacteria and it is not an essential chromosomal element, rather a large plasmid (Agnoli et al., 2012).

\section{Transposon libraries as a tool for drug discovery}

The combination of large-scale transposon mutagenesis with next-generation sequencing (known as Transposoninsertion sequencing (TIS) approach) allows performing global, high-throughput analyses of bacterial genomes to define the essentiality and/or fitness contribution of each genetic feature. TIS methods are based on the preparation of saturated transposon mutant libraries in which each cell carries a single insertion. In the final population, each genetic feature is disrupted multiple times at different sites. Direct sequencing of the transposon-genome junctions, followed by reads mapping on the genome, allows determining the sites of transposon integration. As inactivation of essential genes or functions will result in the loss of the corresponding mutants, features for which mutants cannot be recovered are assumed to be essential (Cain et al. 2020). Importantly, the identification of genes encoding functions that are essential for cell growth and viability is not only important to understand the basic biological processes required to support life, but it is a key strategy to identify novel antimicrobial drug targets (Cardona et al. 2018; Hogan et al. 2018).

By using variations of the TIS experimental approach, 505 essential genes were identified in $B$. pseudomalle (Moule et al. 2014), 406 in B. thailandensis (Baugh et al. 2013) and 508, 383 and 339 in B. cenocepacia K56-2, J2315 and H111 strains, respectively (Baugh et al. 2013; Moule et al. 2014; Wong et al. 2016; Gislason et al. 2017; Higgins et al. 2017). Interestingly, despite a good overlap in the core essential genome, strain-specific differences could be observed among the analyzed closely related $B$. cenocepacia strains. Despite some of these dissimilarities can be ascribed to methodological modifications among studies, other discrepancies reflect strain-specific characteristics (Gislason et al. 2017; Higgins et al. 2017). The comparison of the available essential genomes of $B$. cenocepacia, $B$. pseudomalle $i$, and $B$. thailandensis allowed the identification of a subset of 141 conserved essential genes (Gislason et al. 2017; Higgins et al. 2017). This conserved core essential genome of Burkholderia is enriched in genes encoding functions involved in the maintenance of the cell envelope, including the biosynthesis of lipid A, peptidoglycan and 4-amino-4-deoxy-arabinose (Ara4N) (Gislason et al. 2017). Importantly, while peptidoglycan and lipid A biosynthesis are essential in many Gram-negative bacteria, the essentiality of Ara4N is a peculiarity of Burkholderia species. Moreover, three of the common essential genes, encoding for a lysophospholipid transporter (LplT), a porin (OpcP) and a protein involved lipid A modification by L-Ara4N, were discovered as uniquely essential in the four Burkholderia strains analyzed, supporting their possible use as Burkholderia-specific targets for antibiotic treatment (Gislason et al. 2017).

An important implication of TIS methods is that the generated libraries of transposon mutants can be subjected to growth under various selective conditions to discover genes involved in niche adaptation, pathogenicity and virulence. Genomic regions showing a decreased frequency in transposon insertions over the experimental selection are assumed to be important for growth in the tested conditions. On the contrary, an increase in insertion frequency is associated to genomic features with a disadvantageous effect in the test conditions (Cain et al. 2020).

By using this approach, the identification of the insertion sites of mutants negatively selected during in vivo infection 
allowed to successfully identify virulence factors of $B$. pseudomallei (Moule et al. 2016). Also, genes important for rhizosphere colonisation and phenol degradation were identified in Burkholderia vietnamiensis (O'Sullivan et al. 2007). The comparison of the insertion profiles of transposon mutants of $B$. cenocepacia $\mathrm{J} 2315$ grown in undefined rich nutrient medium (LB) and in M9 minimal medium led to the identification of additional 439 genes found to be crucial for the growth of this bacterium under conditions of nutrient depletion. These included several genes involved in aromatic amino acid biosynthesis (Wong et al. 2016). Genes essential for growth of $B$. cenocepacia H111 in minimal medium and under microoxic conditions $\left(0.5 \% \mathrm{O}_{2}\right)$ were similarly identified (Higgins et al. 2017).

An alternative strategy to identify conditional essential genes in B. cenocepacia was developed and used to detect targets of antibiotics. A library of B. cenocepacia K56-2 conditional growth mutants was created by large-scale delivery of a transposon element carrying an outward tightly regulated Escherichia coli rhamnose-inducible promoter. As transcription of target genes is allowed only in the presence of rhamnose, mutants carrying insertion in essential genes will not grow in the absence of the inducer (Cardona et al. 2006; Bloodworth et al. 2013). Moreover, mutants underexpressing essential genes encoding for targets of molecules with antibacterial activity will show increased sensitivity to the corresponding inhibitor compounds (Bloodworth et al. 2013). Libraries of conditional growth mutants therefore represent an excellent tool to identify targets of antibiotics with unknown mechanism of action. This competitive fitness screen method allowed the identification of the B. cenocepacia cell division protein FtsZ as the target of $\mathrm{C} 109$, a benzothiadiazole derivative with a broad-spectrum antibacterial activity (Hogan et al. 2018). Similarly, a B. cenocepacia two-component system whose inactivation confers hypersensitivity to different classes of antibiotics was found and identified as an optimal target to contrast antibiotic resistance (Cardona et al. 2018).

Despite being limited by the inability to detect non-protein targets of antibiotics, competitive growth of conditional growth mutants under selective conditions allows a rapid screening of many antimicrobial compounds, thus addressing the bottleneck of target identification (Farha and Brown 2016).

\section{Assays to study quorum sensing}

Burkholderia species exploit the cell density-dependent quorum sensing (QS) signaling to synchronize the bacterial population gene expression in response to microenvironment stimuli. As nearly all known Gram-negative bacteria, they mainly possess LuxI/LuxR-like QS systems relying on acyl-homoserine lactone (AHL) autoinducers (Slinger et al. 2019). However, other kind of QS signals are also used by Burkholderia spp. for cell-to-cell communication, including the Burkholderia diffusible signal factor (BDSF) of $B$. cenocepacia (Suppiger et al. 2016) and the 2-alkyl-4(1H)quinolones (AHQs) of B. pseudomallei and B. thailandensis (Coulon et al. 2019). Altogether these form an incredibly complex signalling network that controls hundreds of genes, in particular those encoding virulence factors. Given the importance of the QS regulation in Burkholderia spp., and the emerging interest in this pathway as an alternative antivirulence target, several methods have been used over the years to study it (Table 2).

A widely used experimental strategy to detect the presence of AHLs in bacterial cultures involves the use of Agrobacterium tumefaciens reporter strains (defective for the production of the autoinducer) carrying plasmids that contain a $\operatorname{tra} G:: l a c Z$ fusion, as well as the traR gene. Indeed, $\operatorname{tra} G$ transcription is strictly regulated by the activator TraR, which is activated by the interaction with the autoinducer (an AHL molecule). Since TraR responds to a variety of AHLs, the presence of AHL molecules can be detected through $\beta$-galactosidase assays or using solid media supplemented with 5-bromo-4-chloro-3-indolyl- $\beta$-D-galactopyranoside (X-gal). This technique was exploited by many groups, among them Cui and collaborators who studied the effect of a BDSF analogue on the AHL production of B. cenocepacia $\mathrm{H} 111$ by $\beta$-galactosidase assay (Cui et al. 2019). Two other groups used A. tumefaciens to visualize AHL spots from culture extracts directly on thin layer chromatography (TLC), by overlaying agar medium containing the reporter and incubating overnight, to quantify the signal production in B. cenocepacia and B. lata mutants of QS regulatory genes (Veselova et al. 2016; Jung et al. 2017).

A. tumefaciens bioassay is often used concurrently with the Chromobacterium violaceum $\mathrm{CV} 026$ assay since the two methods are complementary. Indeed, by coupling them it is possible to detect a wider variety of AHLs, given that CV026 and A. tumefaciens strains respond to AHLs with $\mathrm{N}$-acyl side chains from $\mathrm{C}_{4}$ to $\mathrm{C}_{8}$ and $\mathrm{C}_{6}$ to $\mathrm{C}_{12}$ in length, respectively. $C$. violaceum naturally produces the purple pigment violacein, but the CV026 strain (a violacein-negative mutant) restores the pigment production only in the presence of exogenous AHL signals, becoming suitable for an easy QS molecules detection on solid media. Concerning this, the abovementioned studies used this coupled approach on agar plates (Veselova et al. 2016) or on TLC (Jung et al. 2017) highlighting the different AHLs production in their strains. Nonetheless, $C$. violaceum can be also used alone as an indicator strain in agar well-diffusion assays, for instance to test the quorum quenching activity of $B$. cepacia (Malešević et al., 2020). This technique was used to study the poorly characterized QS systems of the plant pathogens 


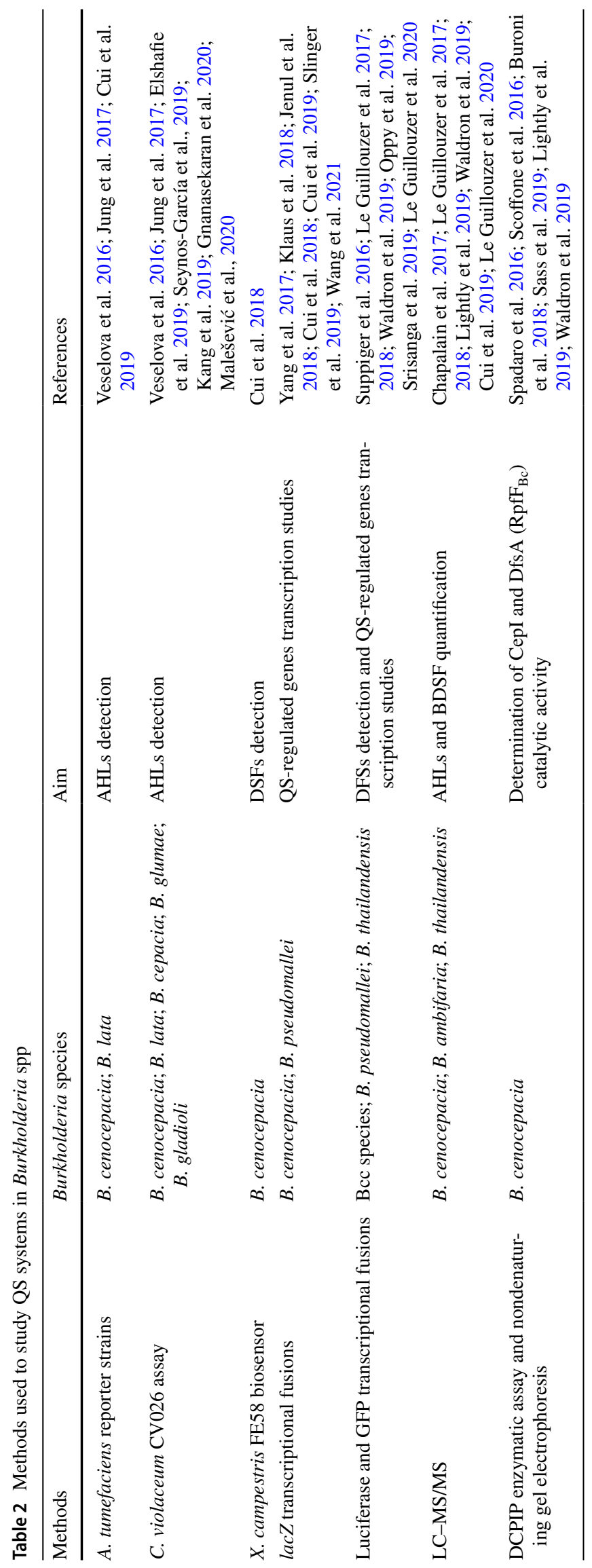


B. glumae and Burkholderia gladioli. Indeed, recent studies exploited the bioassay to measure the AHLs production of a laboratory-evolved clone (Gnanasekaran et al. 2020) and an activated methyl cycle mutant of $B$. glumae (Kang et al. 2019 ) on TLC. Regarding B. gladioli, the $C$. violaceum assay was carried out on agar medium, to analyze the AHL synthesis in mutants of putative QS genes (Seynos-García et al. 2019), but also to find uncharacterized QS genes by using a cosmid genome library conjugated in CV026 reporter strain and selecting the transconjugants showing restored violacein production (Elshafie et al. 2019).

Since many Burkholderia species produce DSF analogues, as the BDSF (Suppiger et al. 2016), the DSF biosensor Xanthomonas campestris FE58 is considered a useful tool for QS research. FE58 is a strain deficient for the DSF production, which carries an engXCA promoter (DSFinducible)-gusA ( $E$. coli $\beta$-glucuronidase) fusion on the pLAFR3 vector. Thus, when FE58 is plated on a medium containing 5-bromo-4-chloro-3-indolyl- $\beta$-D-glucuronide (X-glu) it is possible to visualize the presence of exogenous DSF signals by measuring the blue halo surrounding the colonies of the producer. This method was exploited by Cui and collaborators to find novel regulators involved in the $B$. cenocepacia $\mathrm{H} 111$ QS pathways by screening a Tn5 mutant library (Cui et al. 2018).

Beside the above described reporter microorganisms, the lac $Z$ transcriptional fusion technique is widely used in QS research. Indeed, its simple use and versatility make it one of the most employed molecular methods, which allows an easy visualization of the results by $\beta$-galactosidase or X-gal assays. This approach was widely used in B. cenocepacia H111 where the plasmid pME2-lacZ, containing different QS-regulated promoters, was conjugated directly in the investigated strain to clarify the role of a two component system on QS regulation (Cui et al. 2018) or to determine the effect of a new BDSF analogue (Cui et al. 2019). Also, the same protocol was used by Jenul and collaborators to demonstrate that valdiazen is a novel QS signal in B. cenocepacia (Jenul et al. 2018). A lac $Z$ reporter was exploited also to screen a mutant library of B. cenocepacia in order to find new regulators of QS systems by selecting mutants defective for QS regulatory genes (Yang et al. 2017; Wang et al. 2021). Since QS circuit is the result of an extremely complicated network of interacting proteins, sometimes having redundant roles, the use of lac $Z$ fusions in $E$. coli reporters can be useful to detect specific biological activities in a heterologous background to prevent the interference of additional uncharacterized regulators in the results. For this reason, Klaus et al. used an E. coli reporter to elucidate the role of B. pseudomallei AHLs molecules in the activation of the transcription factor MalR (Klaus et al. 2018). Instead, Slinger et al. exploited this strategy to screen a library of AHL analogs and find modulators of the $B$. cenocepacia
CepR in an E. coli reporter defective for its LuxR-type regulator (Slinger et al. 2019).

Recently, a useful biosensor for the detection of DSF signals was developed in B. cenocepacia $\mathrm{H} 111$ using the sensor plasmid pAN-L15 (Suppiger et al. 2016). This broad host range vector has the luminescence genes $\operatorname{lu} x A B$ under the control of the $b c l A C B$ promoter (strongly activated by BDSF), allowing its transcription only in the presence of a DSF signal. To avoid self-activation of the reporter genes, the plasmid was introduced in a B. cenocepacia $\mathrm{H} 111$ strain deficient for the $r p f F_{b c}$ gene. The biosensor can be used in liquid culture and in cross-streak assays and it is able to respond to several fatty acids with cis-2 configuration even at $\mathrm{nM}$ concentrations (Suppiger et al. 2016; Waldron et al. 2019). Since BDSF is involved in biofilm formation, the same research group created a transcriptional fusion of the $b c l A C B$ promoter with an unstable variant of the GFP to visualize the BDSF production within biofilms, although this biosensor resulted less sensitive than the luxAB-dependent one (Suppiger et al. 2016). Other examples of luminescencedependent reporters relying on the promoterless luxCDABE operon are present in literature, such as the plasmid pMS402 used in B. cenocepacia to easily detect changes in cepI and cepR transcription (Oppy et al. 2019), the pSB401 in E. coli to quantify the AHL production in B. pseudomallei (Srisanga et al. 2019), and the mini-CTX-lux integration vector in B. thailandensis to shed light on its complex QS circuitry (Le Guillouzer et al. 2017; 2018; 2020).

Biological reporters are reliable tools in QS studies but, for a more precise identification and quantification of autoinducers, the use of more powerful analytical techniques is often necessary. In this case, liquid chromatography with tandem mass spectrometry (LC-MS/MS) is currently the method of choice, allowing the fine separation of the culture supernatant extracts on a HPLC column, followed by the sensitive detection of signal molecules such as AHLs (Lightly et al. 2019; Chapalain et al. 2017; Le Guillouzer et al. 2017; 2018; 2020) or BDSF (Waldron et al. 2019; Cui et al. 2019) by mass spectrometer.

The characterization of QS mechanisms goes also through the study of the enzymes involved, and in particular of the autoinducer synthases. To this end, different enzymatic assays were used to determine the catalytic activity of these proteins, as well as to test the potentiality of new inhibitors. To test the catalytic activity of B. cenocepacia CepI, a spectrophotometric assay that measures the formation of the holo-acyl carrier protein (ACP) during the biosynthetic reaction was used. Indeed, through a redox reaction between the released free thiol of ACP and the dichlorophenylindophenol (DCPIP) it is possible to determine the catalytic activity by measuring the absorbance at $600 \mathrm{~nm}$ (Scoffone et al. 2016; Buroni et al. 2018; Sass et al. 2019; Lightly et al. 2019). Similarly, the thioesterase activity of the other main 
B. cenocepacia QS synthase DsfA $\left(\mathrm{RpF}_{\mathrm{Bc}}\right)$, responsible for the BDSF biosynthesis, was assessed using the DCPIP reagent (Spadaro et al. 2016), or alternatively by checking the holo-ACP release with conformation-sensitive nondenaturing gel electrophoresis (Spadaro et al. 2016; Waldron et al. 2019).

\section{Animal models to study Burkholderia infections}

The use of different biological models to study armful Burkholderia genus bacteria has been fundamental to acquire nowadays' knowledge on virulence and pathogenesis, mostly in the field of cystic fibrosis; different organisms are available today, differing in their complexity, research adaptability, and required laboratory setting.

Invertebrate infection models lacking the adaptive immune system can be used to study both cellular and humoral innate immune response, which involves antimicrobial peptides production, phagocytosis, and hemolymph clotting (Wong et al. 2018). Caenorhabditis elegans is one of the first tested invertebrate hosts to support Burkholderia infection (Köthe et al. 2003); the availability of tools for its genetic manipulation makes it an attractive organism for the identification of virulence factors and their conservation among different species. Moreover, its transparency can be employed to monitor bacterial localization and invasion, using GFP tagged cells (Köthe et al. 2003). Two methods can be applied to study Burkholderia cepacia complex infection (Tedesco et al. 2015): the "slow-killing" one produces a persistent intestinal infection as the nematode is fed with bacteria present in the nematode growth medium (NGM). Results can be observed from 1 to 3 days after larvae inoculation when bacteria eventually colonized the gut causing worms death and recalling an infection-like process (Wong et al. 2018; Tedesco et al. 2015). The second one, called "fast-killing," is used to identify potential toxins as bacteria are grown on a filter posed on a high-osmolarity medium (e.g., PGS) (Wong et al. 2018; Tedesco et al. 2015); the filter is then removed, and the larvae are added to the plate. Within $24 \mathrm{~h}$ of incubation, the produced toxins can temporarily paralyze C. elegans and sometimes kill it (Wong et al. 2018; Tedesco et al. 2015). In-liquid analysis involves C. elegans interaction with the pathogen of interest in the presence or absence of antibiotics or quorum sensing inhibitors (Scoffone et al. 2016), and can be extended to study $B$. mallei and B. pseudomallei as well (Trottmann et al. 2019; Chen et al. 2019); again, virulence is quantitatively measured. Unfortunately, past studies highlighted C. elegans poor correlation with both mammalian and other alternative models (Uehlinger et al. 2009; Seed and Dennis 2008), producing contradictory and mixed results; this variation is probably linked to the two killing methods displayed by the bacteria and to factors such as the age of the worms and the medium used.

Drosophila melanogaster, having a fully sequenced genome, has emerged as an alternative and easy to manipulate model (Allen et al. 2016; Castonguay-Vanier et al. 2010): its innate immune system is very similar to the human one, allowing the identification of common immunity factors via gene microarrays. To infect fruit flies, the nicking method proved to be effective, highly reproducible, and accurate (Castonguay-Vanier et al. 2010), as a needle dipped into a bacterial suspension is used to prick Drosophila in the thorax. Furthermore, to study Bcc infection outcomes in D. melanogaster on different dietary regimens, Allen et al. (2016) directly injected the bacterial suspension inside the flies using a sterile capillary needle. According to the strain, from $50 \mathrm{~h}$ to 6 days may be needed to record flies' death (Allen et al. 2016; Castonguay-Vanier et al. 2010).

One of the probably most used insect hosts for Burkholderia genus infection is Galleria melonella. This model provides a fast, simple, and cost-effective platform, as larvae do not need to be fed and an output is available in $72 \mathrm{~h}$ (Costabile et al. 2020; Srinon et al. 2019; Fathy et al., 2019; Papp-Wallace et al. 2017; Seed and Dennis 2008). Bacteria inoculation requires an injection in one of the hindmost prolegs, while pathogenesis signs can be easily followed, as they involve melanization and motility impairment; finally, infection in Galleria is sensitive as in mammalian models, producing comparable results with the rat agar beads model for lung pathology (Seed and Dennis 2008).

Higher organism models of infection include the Danio rerio embryo model. With an early development innate immune system, it is useful to study bacteria survival after phagocytosis; in addition, its immune response shows significant homology to the major inflammatory factors involved in humans, as the Toll-Like Receptors (TLRs) and the complement system (Gomes et al. 2018). Unfortunately, this model cannot fully resemble a cystic fibrosis-like infection: Vergunst et al. (2010) proved that upon infection many phagocytes recruited and activated were macrophages, showing a bias towards this response. As for nematodes, zebrafish embryos are transparent, providing a valuable tool to follow invasion and dissemination over time, while bacteria are inoculated through the caudal vein and results may be available within $24 \mathrm{~h}$ post-infection (Gomes et al. 2018).

To conclude, the most complete biological model to study B. cepacia complex infection is the murine one, with a total of 15 mice engineered to further study the different disease degrees of cystic fibrosis (O'Neal et al. 1993; Ratcliff et al. 1993; Dorin et al. 1994; Colledge et al. 1995; Hasty et al. 1995; van Doorninck et al. 1995; Zeiher et al. 1995; Delaney et al. 1996; Rozmahel et al. 1996; Fisher et al. 2012). These mice models can be divided into two categories: the first 
one is originated with a "replacement strategy," with mice unable to produce CFTR at all (Snouwaert et al. 1992; Dorin et al. 1994); the second one, originated with an "insertional strategy," replicates the known clinical mutations with disease severity, survival rates, and pathology unique to each model (Ratcliff et al. 1993; O'Neal et al. 1993; Colledge et al. 1995; Hasty et al. 1995; van Doorninck et al. 1995; Zeiher et al. 1995; Delaney et al. 1996; Rozmahel et al. 1996). On the other hand, many of these mice developed a range of intestinal complications that would cause fatality: to ameliorate this problem, Durie et al. (2004) produced a long-lived $\mathrm{C} 57 \mathrm{BL} / 6 \mathrm{~J} \mathrm{Cftr}^{-/-}$mouse displaying human lung pathology and progressive multi-organ affliction. Despite the efforts, none of the previous models could mimic a spontaneous bacterial infection: factors involved may be the relatively short life span of $\mathrm{Cftr}^{-/-}$mutants, living in a sterile environment, the smaller airway size, and the presence of a nonCFTR calcium-activated $\mathrm{Cl}^{-}$channel, all conditions which are not comparable to human (Wilke et al. 2011; Clarke et al. 1994). Bcc bacteria are also important pathogens in patients affected by the autoimmune chronic granulomatous disease (CGD), which impairs phagocytosis and bacterial clearance: to this end, gp91 $1^{\text {phox-/- }}$ and $\mathrm{p} 47^{\text {phox-/- }}$ mice were generated (Pizzolla et al. 2012; Sousa et al. 2007). Compared to a CF background, they present bacteria persistence in both macrophages and neutrophils but greatly differ in the mucociliary clearance and in the compartmentalized infection. Finally, to establish a chronic, non-lethal lung $B$. cepacia infection, the rat agar beads model in C57BL/6 J mice can be employed (Bragonzi et al. 2017): the use of bacteria imbedded in agar beads is useful to study tissue invasion and histopathology in WT and $\mathrm{Cftr}^{-/-}$mice. Beads are inoculated intratracheally and mice are sacrificed after $72 \mathrm{~h}$. This model resembles a highly neutrophilic infiltrate in the lung and a marked pulmonary infection and inflammation, fully overlapping the devastating condition found in cystic fibrosis patients (Bragonzi et al. 2017).

All the previously considered Burkholderia species (including B. mallei and B. pseudomallei) can be intratracheally or intranasally inoculated in BALB/c and C57BL/6 J mice to assess survival, proving how these models are useful also for vaccine development (Saikh et al. 2019; Amemiya et al. 2020; Khakhum et al. 2019; Sabet and Griffith, 2020; Vanhoutte et al. 2017).

\section{Conclusions}

Bacteria belonging to the Burkholderia genus are heterogeneous and versatile, able to survive in different environments and to cause diseases in plant and animal hosts. The study and characterization of these microorganisms is complicated due to their large genomes and drug resistance. Here we reviewed the main techniques used in the last few years to try to elucidate the taxonomy, genomics, virulence, resistance and ability to cause infections of these opportunistic pathogens. Taxonomy is evolving very fast thanks to new tools which lead to the precise identification of species: this is not easy because of the similarity among genomes, but very important to properly characterize bacteria. Indeed, the Burkholderia genus was initially classified as Pseudomonas, but many differences exist between these pathogens.

At the same time, gene deletion techniques and transposon libraries revealed essential to properly assess gene functions and find novel drug targets. This is complicated by the poor genetic manipulation of some species; nonetheless, important progresses have been made in the last few years.

The study of quorum sensing has the double advantage of leading to the understanding of gene regulation and of characterization of new potential antivirulence targets, being this pathway involved in the regulation of the expression of virulence-related genes. In this way, the choice of the best assay is fundamental.

Finally, an overview of animal models suitable to study the ability of Burkholderia bacteria to cause infections has been reported. Also in this case, many alternatives are available and the choice should be performed based on the strain, disease to be studied, but also costs.

Overall, design and optimization of innovative procedures are fundamental to get new insights into Burkholderia bacteria and this review should have given a comprehensive summary of the most useful tools.

Author contribution VCS, GT, GB, SI, AI, and SB conducted the bibliography revision and wrote the manuscript. VCS performed the artwork. All the authors approved the manuscript.

Funding This work was supported by the Italian Ministry of Education, University and Research (MIUR) (Dipartimenti di Eccellenza, Program 2018-2022) to Department of Biology and Biotechnology, "L. Spallanzani," University of Pavia.

\section{Declarations}

Ethical approval This article does not contain any studies with human participants or animals performed by any of the author.

Conflict of interest The authors declare no competing interests.

\section{References}

Abdu A, Juarez-Lara G, Dennis JJ (2018) Development of an Sce-I mutagenesis system for Burkholderia cepacia complex strains. J Microbiol Methods 146:16-21. https://doi.org/10.1016/j.mimet. 2018.01.011

Agnoli K, Schwager S, Uehlinger S, Vergunst A, Viteri DF, Nguyen DT, Sokol PA, Carlier A, Eberl L (2012) Exposing the third 
chromosome of Burkholderia cepacia complex strains as a virulence plasmid. Mol Microbiol 83:362-378. https://doi. org/10.1111/j.1365-2958.2011.07937.x

Allen VW, O'Connor RM, Ulgherait M, Zhou CG, Stone EF, Hill VM, Murphy KR, Canman JC, Ja WW, Shirasu-Hiza MM (2016) Period-regulated feeding behavior and TOR signaling modulate survival of infection. Curr Biol 26:184-194. https:// doi.org/10.1016/j.cub.2015.11.051

Amemiya K, Dankmeyer JL, Bearss JJ, Zeng X, Stonier SW, Soffler C, Cote CK, Welkos SL, Fetterer DP, Chance TB, Trevino SR, Worsham PL, Waag DM (2020) Dysregulation of TNF- $\alpha$ and IFN- $\gamma$ expression is a common host immune response in a chronically infected mouse model of melioidosis when comparing multiple human strains of Burkholderia pseudomallei. BMC Immunol 21:5. https://doi.org/10.1186/ s12865-020-0333-9

Amemiya K, Dankmeyer JL, Biryukov SS, Treviño SR, Klimko CP, Mou SM, Fetterer DP, Garnes PG, Cote CK, Worsham PL, DeShazer D (2019) Deletion of two genes in Burkholderia pseudomallei MSHR668 that target essential amino acids protect acutely infected BALB/c mice and promote long term survival. Vaccines 7:196. https://doi.org/10.3390/vaccines7040196

Andrade A, Tavares-Carreón F, Khodai-Kalaki M, Valvano MA (2016) Tyrosine phosphorylation and dephosphorylation in Burkholderia cenocepacia affect biofilm formation, growth under nutritional deprivation, and pathogenicity. Appl Environ Microbiol 82:843-856. https://doi.org/10.1128/AEM.03513-15

Baugh L, Gallagher LA, Patrapuvich R, Clifton MC, Gardberg AS, Edwards TE, Armour B, Begley DW, Dieterich SH, Dranow DM, Abendroth J, Fairman JW, Fox D, Staker BL, Phan I, Gillespie A, Choi R, Nakazawa-Hewitt S, Nguyen MT, Napuli A, Barrett L, Buchko GW, Stacy R, Myler PJ, Stewart LJ, Manoil C, Van Voorhis WC (2013) Combining functional and structural genomics to sample the essential Burkholderia structome. PLoS One 8:e53851. https://doi.org/10.1371/journal.pone.0053851

Bloodworth RAM, Gislason AS, Cardona ST (2013) Burkholderia cenocepacia conditional growth mutant library created by random promoter replacement of essential genes. MicrobiologyOpen 2:243-258. https://doi.org/10.1002/mbo3.71

Bragonzi A, Paroni M, Pirone L, Coladarci I, Ascenzioni F, Bevivino A (2017) Environmental Burkholderia cenocepacia strain enhances fitness by serial passages during long-term chronic airways infection in mice. Int J Mol Sci 18:2417. https://doi.org/10.3390/ijms1 8112417

Burkholder WH (1950) Sour skin, a bacterial rot of onion bulbs. Phytopathology 40:115-117

Buroni S, Scoffone VC, Fumagalli M, Makarov V, Cagnone M, Trespidi G, De Rossi E, Forneris F, Riccardi G, Chiarelli LR (2018) Investigating the mechanism of action of diketopiperazines inhibitors of the Burkholderia cenocepacia quorum sensing synthase CepI: a site-directed mutagenesis study. Front Pharmacol 9:836. https://doi.org/10.3389/fphar.2018.00836

Cain AK, Barquist L, Goodman AL, Paulsen IT, Parkhill J, van Opijnen T (2020) A decade of advances in transposon-insertion sequencing. Nat Rev Genet 21:526-540. https://doi.org/10.1038/ s41576-020-0244-x

Cardona ST, Choy M, Hogan AM (2018) Essential two-component systems regulating cell envelope functions: opportunities for novel antibiotic therapies. J Membr Biol 251:75-89. https://doi.org/10. 1007/s00232-017-9995-5

Cardona ST, Mueller CL, Valvano MA (2006) Identification of essential operons with a rhamnose-inducible promoter in Burkholderia cenocepacia. Appl Environ Microbiol 72:2547-2555. https://doi. org/10.1128/AEM.72.4.2547-2555.2006

Castonguay-Vanier J, Vial L, Tremblay J, Déziel E (2010) Drosophila melanogaster as a model host for the Burkholderia cepacia complex. PLoS One 5:e11467. https://doi.org/10.1371/journal. pone.0011467

Chapalain A, Groleau MC, Le Guillouzer S, Miomandre A, Vial L, Milot S, Déziel E (2017) Interplay between 4-hydroxy-3-methyl2-alkylquinoline and $\mathrm{N}$-acyl-homoserine lactone signaling in a Burkholderia cepacia complex clinical strain. Front Microbiol 8:1021. https://doi.org/10.3389/fmicb.2017.01021

Chen YL, Hsu DW, Hsueh PT, Chen JA, Shih PJ, Lee S, Lin HH, Chen YS (2019) Distinct pathogenic patterns of Burkholderia pseudomallei isolates selected from Caenorhabditis elegans and Dictyostelium discoideum models. Am J Trop Med Hyg 101:736-745. https://doi.org/10.4269/ajtmh.19-0052

Clarke LL, Grubb BR, Yankaskas JR, Cotton CU, McKenzie A, Boucher RC (1994) Relationship of a non-cystic fibrosis transmembrane conductance regulator-mediated chloride conductance to organ-level disease in $\mathrm{Cftr}^{(--)}$mice. Proc Natl Acad Sci U S A 91:479-483. https://doi.org/10.1073/pnas.91.2.479

Colledge WH, Abella BS, Southern KW, Ratcliff R, Jiang C, Cheng SH, MacVinish LJ, Anderson JR, Cuthbert AW, Evans MJ (1995) Generation and characterization of a delta F508 cystic fibrosis mouse model. Nat Genet 10:445-452. https://doi.org/10.1038/ ng0895-445

Costabile G, Provenzano R, Azzalin A, Scoffone VC, Chiarelli LR, Rondelli V, Grillo I, Zinn T, Lepioshkin A, Savina S, Miro A, Quaglia F, Makarov V, Coenye T, Brocca P, Riccardi G, Buroni S, Ungaro F (2020) PEGylated mucus-penetrating nanocrystals for lung delivery of a new FtsZ inhibitor against Burkholderia cenocepacia infection. Nanomedicine 23:102-113. https://doi. org/10.1016/j.nano.2019.102113

Coulon PML, Groleau MC, Déziel E (2019) Potential of the Burkholderia cepacia complex to produce 4-hydroxy-3-methyl-2-alkyquinolines. Front Cell Infect Microbiol 9:33. https://doi.org/10.3389/ fcimb.2019.00033

Cui C, Song S, Yang C, Sun X, Huang Y, Li K, Zhao S, Zhang Y, Deng Y (2019) Disruption of quorum sensing and virulence in Burkholderia cenocepacia by a structural analogue of the cis-2-dodecenoic acid signal. Appl Environ Microbiol 85:e00105-e119. https://doi.org/10.1128/AEM.00105-19

Cui C, Yang C, Song S, Fu S, Sun X, Yang L, He F, Zhang LH, Zhang Y, Deng Y (2018) A novel two-component system modulates quorum sensing and pathogenicity in Burkholderia cenocepacia. Mol Microbiol 108:32-44. https://doi.org/10.1111/mmi.13915

De Dios J, Martínez CL, Tato M, Morosini MI, Cobo M, Del Campo $\mathrm{R}$, Canton R (2016) Comparison between MALDI-TOF and recA gene sequencing for the identification of Burkholderia cepacia complex species isolated in a cystic fibrosis unit. J Cyst Fibros 15(S1):S75. https://doi.org/10.1016/S1569-1993(16)30333-2

Delaney SJ, Alton EW, Smith SN, Lunn DP, Farley R, Lovelock PK, Thomson SA, Hume DA, Lamb D, Porteous DJ, Dorin JR, Wainwright BJ (1996) Cystic fibrosis mice carrying the missense mutation G551D replicate human genotype-phenotype correlations. EMBO J 15:955-963

Depoorter E, De Canck E, Peeters C, Wieme AD, Cnockaert M, Zlosnik JEA, LiPuma JJ, Coenye T, Vandamme P (2020) Burkholderia cepacia complex taxon $\mathrm{K}$ : where to split? Front Microbiol 11:1594. https://doi.org/10.3389/fmicb.2020.01594

Dobritsa AP, Samadpour M (2016) Transfer of eleven species of the genus Burkholderia to the genus Paraburkholderia and proposal of Caballeronia gen. nov. to accommodate twelve species of the genera Burkholderia and Paraburkholderia. Int J Syst Evol Microbiol 66:2836-2846. https://doi.org/10.1099/ijsem.0.001065

Dorin JR, Stevenson BJ, Fleming S, Alton EW, Dickinson P, Porteous DJ (1994) Long-term survival of the exon 10 insertional cystic fibrosis mutant mouse is a consequence of low level residual wild-type Cftr gene expression. Mamm Genome 5:465-472. https://doi.org/10.1007/BF00369314 
Durie PR, Kent G, Phillips MJ, Ackerley CA (2004) Characteristic multiorgan pathology of cystic fibrosis in a long-living cystic fibrosis transmembrane regulator knockout murine model. Am J Pathol 164:1481-1493. https://doi.org/10.1016/S0002-9440(10) 63234-8

Elshafie HS, Devescovi G, Venturi V, Camele I, Bufo SA (2019) Study of the regulatory role of $\mathrm{N}$-acyl homoserine lactones mediated quorum sensing in the biological activity of Burkholderia gladioli pv. agaricicola causing soft rot of Agaricus spp. Front Microbiol 10:2695. https://doi.org/10.3389/fmicb.2019.02695

Estrada-de Los Santos P, Palmer M, Chávez-Ramírez B, Beukes C, Steenkamp ET, Briscoe L, Khan N, Maluk M, Lafos M, Humm E, Arrabit M, Crook M, Gross E, Simon MF, Dos Reis Junior FB, Whitman WB, Shapiro N, Poole PS, Hirsch AM, Venter SN, James EK (2018) Whole genome analyses suggests that Burkholderia sensu lato contains two additional novel genera (Mycetohabitans gen. nov., and Trinickia gen. nov.): Implications for the evolution of diazotrophy and nodulation in the Burkholderiaceae. Genes (Basel) 9:389. https://doi.org/10.3390/ genes 9080389

Farha MA, Brown ED (2016) Strategies for target identification of antimicrobial natural products. Nat Prod Rep 33:668-680. https:// doi.org/10.1039/C5NP00127G

Fathy Mohamed Y, Scott NE, Molinaro A, Creuzenet C, Ortega X, Lertmemongkolchai G, Tunney MM, Green H, Jones AM, DeShazer D, Currie BJ, Foster LJ, Ingram R, De Castro C, Valvano MA (2019) A general protein $O$-glycosylation machinery conserved in Burkholderia species improves bacterial fitness and elicits glycan immunogenicity in humans. J Biol Chem 294:13248-13268. https://doi.org/10.1074/jbc.RA119.009671

Fergusson CH, Coloma J, Valentine MC, Haeckl FPJ, Linington RG (2020) Custom matrix-assisted laser desorption ionization-time of flight mass spectrometric database for identification of environmental isolates of the genus Burkholderia and related genera. Appl Environ Microbiol 86:e00354-e320. https://doi.org/10. 1128/AEM.00354-20

Fisher JT, Liu X, Yan Z, Luo M, Zhang Y, Zhou W, Lee BJ, Song Y, Guo C, Wang Y, Lukacs GL, Engelhardt JF (2012) Comparative processing and function of human and ferret cystic fibrosis transmembrane conductance regulator. J Biol Chem 287:2167321685. https://doi.org/10.1074/jbc.M111.336537

Flannagan RS, Linn T, Valvano MA (2008) A system for the construction of targeted unmarked gene deletions in the genus Burkholderia: targeted unmarked gene deletions in Burkholderia. Environ Microbiol 10:1652-1660. https://doi.org/10.1111/j.1462-2920. 2008.01576.x

Frickmann H, Neubauer H, Loderstaedt U, Derschum H, Hagen RM (2014) $r p s U$-based discrimination within the genus Burkholderia. Eur J Microbiol Immunol (bp) 4:106-116. https://doi.org/ 10.1556/eujmi.4.2014.2.3

Furlan JPR, Pitondo-Silva A, Braz VS, Gallo IFL, Stehling EG (2019) Evaluation of different molecular and phenotypic methods for identification of environmental Burkholderia cepacia complex. World J Microbiol Biotechnol 35:39. https://doi.org/10.1007/ s11274-019-2614-0

Gassiep I, Armstrong M, Norton RE (2019) Identification of Burkholderia pseudomallei by Use of the Vitek Mass Spectrometer. J Clin Microbiol 57:e00081-e119. https://doi.org/10.1128/JCM. 00081-19

Gautam V, Sharma M, Singhal L, Kumar S, Kaur P, Tiwari R, Ray $P$ (2017) MALDI-TOF mass spectrometry: An emerging tool for unequivocal identification of non-fermenting Gram-negative bacilli. Indian J Med Res 145:665-672. https://doi.org/10.4103/ ijmr.IJMR_1105_15

Gislason AS, Turner K, Domaratzki M, Cardona ST (2017) Comparative analysis of the Burkholderia cenocepacia K56-2 essential genome reveals cell envelope functions that are uniquely required for survival in species of the genus Burkholderia. Microb Genom 3:e000140. https://doi.org/10.1099/ mgen.0.000140

Gnanasekaran G, Lim JY, Hwang I (2020) Disappearance of quorum sensing in Burkholderia glumae during experimental evolution. Microb Ecol 79:947-959. https://doi.org/10.1007/ s00248-019-01445-0

Gomes MC, Tasrini Y, Subramoni S, Agnoli K, Feliciano JR, Eberl L, Sokol P, O'Callaghan D, Vergunst AC (2018) The afc antifungal activity cluster, which is under tight regulatory control of ShvR, is essential for transition from intracellular persistence of Burkholderia cenocepacia to acute pro-inflammatory infection. PLoS Pathog 14:e1007473. https://doi.org/10.1371/journ al.ppat. 1007473

Haeckl FPJ, Baldim JL, Ikakova D, Kurita KL, Soares MG, Linington RG (2019) A selective genome-guided method for environmental Burkholderia isolation. J Ind Microbiol Biotechnol 46:345-362. https://doi.org/10.1007/s10295-018-02121-x

Hamad MA, Skeldon AM, Valvano MA (2010) Construction of aminoglycoside-sensitive Burkholderia cenocepacia strains for use in studies of intracellular bacteria with the gentamicin protection assay. Appl Environ Microbiol 76(10):3170-3176. https://doi. org/10.1128/AEM.03024-09

Hasty P, O’Neal WK, Liu KQ, Morris AP, Bebok Z, Shumyatsky GB, Jilling T, Sorscher EJ, Bradley A, Beaudet AL (1995) Severe phenotype in mice with termination mutation in exon 2 of cystic fibrosis gene. Somat Cell Mol Genet 21:177-187. https://doi.org/ 10.1007/BF02254769

Higgins S, Sanchez-Contreras M, Gualdi S, Pinto-Carbó M, Carlier A, Eberl L (2017) The essential genome of Burkholderia cenocepacia H111. J Bacteriol 199:e00260-e317. https://doi.org/10. 1128/JB.00260-17

Ho CS, Jean N, Hogan CA, Blackmon L, Jeffrey SS, Holodniy M, Banaei N, Saleh AAE, Ermon S, Dionne J (2019) Rapid identification of pathogenic bacteria using Raman spectroscopy and deep learning. Nat Commun 10:4927. https://doi.org/10.1038/ s41467-019-12898-9

Hogan AM, Rahman ASMZ, Lightly TJ, Cardona ST (2019) A broadhost-range CRISPRi toolkit for silencing gene expression in Burkholderia. ACS Synth Biol 8:2372-2384. https://doi.org/10. 1021/acssynbio.9b00232

Hogan AM, Scoffone VC, Makarov V, Gislason AS, Tesfu H, Stietz MS, Brassinga AKC, Domaratzki M, Li X, Azzalin A, Biggiogera M, Riabova O, Monakhova N, Chiarelli LR, Riccardi G, Buroni S, Cardona ST (2018) Competitive fitness of essential gene knockdowns reveals a broad-spectrum antibacterial inhibitor of the cell division protein FtsZ. Antimicrob Agents Chemother 62:e01231-e1318. https://doi.org/10.1128/AAC.01231-18

Israyilova A, Buroni S, Forneris F, Scoffone VC, Shixaliyev NQ, Riccardi G, Chiarelli LR (2016) Biochemical characterization of glutamate racemase-a new candidate drug target against Burkholderia cenocepacia infections. PLoS One 11:e016350. https:// doi.org/10.1371/journal.pone.0167350

Jenul C, Sieber S, Daeppen C, Mathew A, Lardi M, Pessi G, Hoepfner D, Neuburger M, Linden A, Gademann K, Eberl L (2018) Biosynthesis of fragin is controlled by a novel quorum sensing signal. Nat Commun 9:1297. https://doi.org/10.1038/ s41467-018-03690-2

Jin Y, Zhou J, Zhou J, Hu M, Zhang Q, Kong N, Ren H, Liang L, Yue J (2020) Genome-based classification of Burkholderia cepacia complex provides new insight into its taxonomic status. Biol Direct 15:6. https://doi.org/10.1186/s13062-020-0258-5

Jung HI, Kim YJ, Lee YJ, Lee HS, Lee JK, Kim SK (2017) Mutation of the cyclic di-GMP phosphodiesterase gene in Burkholderia lata SK875 attenuates virulence and enhances biofilm 
formation. J Microbiol 55:800-808. https://doi.org/10.1007/ s12275-017-7374-7

Kang Y, Kim H, Goo E, Jeong H, An JH, Hwang I (2019) Unraveling the role of quorum sensing-dependent metabolic homeostasis of the activated methyl cycle in a cooperative population of Burkholderia glumae. Sci Rep 9:11038. https://doi.org/10.1038/ s41598-019-47460-6

Kenna DTD, Lilley D, Coward A, Martin K, Perry C, Pike R, Hill R, Turton JF (2017) Prevalence of Burkholderia species, including members of Burkholderia cepacia complex, among UK cystic and non-cystic fibrosis patients. J Med Microbiol 66:490-450. https://doi.org/10.1099/jmm.0.000458

Khakhum N, Bharaj P, Myers JN, Tapia D, Walker DH, Endsley JJ, Torres AG (2019) Evaluation of Burkholderia mallei $\Delta$ tonB $\Delta h c p 1$ (CLH001) as a live attenuated vaccine in murine models of glanders and melioidosis. PLoS Negl Trop Dis 13:e0007578. https://doi.org/10.1371/journal.pntd.0007578

Kiekens S, Sass A, Van Nieuwerburgh F, Deforce D, Coenye T (2018) The small RNA ncS35 regulates growth in Burkholderia cenocepacia J2315. mSphere 3:e00579-17. https://doi.org/10.1128/ mSphere.00579-17

Klaus JR, Deay J, Neuenswander B, Hursh W, Gao Z, Bouddhara T, Williams TD, Douglas J, Monize K, Martins P, Majerczyk C, Seyedsayamdost MR, Peterson BR, Rivera M, Chandler JR (2018) Malleilactone is a Burkholderia pseudomallei virulence factor regulated by antibiotics and quorum sensing. J Bacteriol 200:e00008-18. https://doi.org/10.1128/JB.00008-18

Kloß S, Lorenz B, Dees S, Labugger I, Rösch P, Popp J (2015) Destruction-free procedure for the isolation of bacteria from sputum samples for Raman spectroscopic analysis. Anal Bioanal Chem 407:8333-8341. https://doi.org/10.1007/s00216-015-8743-x

Köthe M, Antl M, Huber B, Stoecker K, Ebrecht D, Steinmetz I, Eberl L (2003) Killing of Caenorhabditis elegans by Burkholderia cepacia is controlled by the cep quorum-sensing system. Cell Microbiol 5:343-351. https://doi.org/10.1046/j.1462-5822.2003. 00280.x

Le Guillouzer S, Groleau MC, Déziel E (2017) The complex quorum sensing circuitry of Burkholderia thailandensis is both hierarchically and homeostatically organized. mBio 8:e1861-17. https:// doi.org/10.1128/mBio.01861-17

Le Guillouzer S, Groleau MC, Déziel E (2018) Two rsaM homologues encode central regulatory elements modulating quorum sensing in Burkholderia thailandensis. J Bacteriol 200:e00727-e817. https://doi.org/10.1128/JB.00727-17

Le Guillouzer S, Groleau MC, Mauffrey F, Déziel E (2020) ScmR, a global regulator of gene expression, quorum sensing, $\mathrm{pH}$ homeostasis, and virulence in Burkholderia thailandensis. J Bacteriol 202:e00776-e819. https://doi.org/10.1128/JB.00776-19

Lee C, Mannaa M, Kim N, Kim J, Choi Y, Kim SH, Jung B, Lee H-H, Lee J, Seo Y-S (2019) Stress Tolerance and VirulenceRelated Roles of Lipopolysaccharide in Burkholderia glumae. Plant Pathol J 35:445-458. https://doi.org/10.5423/PPJ.OA.04. 2019.0124

Lennings J, Mayer C, Makhlouf M, Brötz-Oesterhelt H, Schwarz S (2019) Polar localization of the ATPase ClpV-5 occurs independent of type VI secretion system apparatus proteins in Burkholderia thailandensis. BMC Res Notes 12:109. https://doi.org/ 10.1186/s13104-019-4141-3

Li R, Shi H, Zhao X, Liu X, Duan Q, Song C, Chen H, Zheng W, Shen Q, Wang M, Wang X, Gong K, Yin J, Zhang Y, Li A, Fu J (2021) Development and application of an efficient recombineering system for Burkholderia glumae and Burkholderia plantarii. Microb Biotechnol 14:1809-1826. https://doi.org/10.1111/17517915.13840

Lightly TJ, Frejuk KL, Groleau MC, Chiarelli LR, Ras C, Buroni S, Déziel E, Sorensen JL, Cardona ST (2019) Phenylacetyl coenzyme A, not phenylacetic acid, attenuates CepIR-regulated virulence in Burkholderia cenocepacia. Appl Environ Microbiol 85:e01594-e1619. https://doi.org/10.1128/AEM.01594-19

Lin QH, Lv YY, Gao ZH, Qiu LH (2020) Pararobbsia silviterrae gen. nov., sp. nov., isolated from forest soil and reclassification of Burkholderia alpina as Pararobbsia alpina comb. nov. Int J Syst Evol Microbiol 70:1412-1420. https://doi.org/10.1099/ijsem.0. 003932

Lopes-Santos L, Castro DBA, Ferreira-Tonin M, Corrêa DBA, Weir BS, Park D, Ottoboni LMM, Neto JR, Destéfano SAL (2017) Reassessment of the taxonomic position of Burkholderia andropogonis and description of Robbsia andropogonis gen. nov., comb. nov. Antonie Van Leeuwenhoek 110:727-736. https://doi.org/10.1007/s10482-017-0842-6

Malešević M, Stanisavljević N, Novović K, Polović N, Vasiljević Z, Kojić M, Jovčić B (2020) Burkholderia cepacia YtnP and Y2-aiiA lactonases inhibit virulence of Pseudomonas aeruginosa via quorum quenching activity. Microb Pathog 149:104561. https://doi.org/10.1016/j.micpath.2020.104561

Martinucci M, Roscetto E, Iula VD, Votsi A, Catania MR, De Gregorio E (2016) Accurate identification of members of the Burkholderia cepacia complex in cystic fibrosis sputum. Lett Appl Microbiol 62:221-229. https://doi.org/10.1111/lam.12537

Moawad AA, Silge A, Bocklitz T, Fischer K, Rösch P, Roesler U, Elschner MC, Popp J, Neubauer HA (2019) Machine learning-based Raman spectroscopic assay for the identification of Burkholderia mallei and related species. Molecules 24:4516. https://doi.org/ 10.3390/molecules24244516

Moule MG, Hemsley CM, Seet Q, Guerra-Assunção JA, Lim J, SarkarTyson M, Clark TG, Tan PBO, Titball RW, Cuccui J, Wren BW (2014) Genome-wide saturation mutagenesis of Burkholderia pseudomallei K96243 predicts essential genes and novel targets for antimicrobial development. mBio 11(5):e00926-13. https:// doi.org/10.1128/mBio.00926-13

Moule MG, Spink N, Willcocks S, Lim J, Guerra-Assunção JA, Cia F, Champion OL, Senior NJ, Atkins HS, Clark T, Bancroft GJ, Cuccui J, Wren BW (2016) Characterization of new virulence factors involved in the intracellular growth and survival of Burkholderia pseudomallei. Infect Immun 84:701-710. https://doi. org/10.1128/IAI.01102-15

O’Neal WK, Hasty P, McCray PB Jr, Casey B, Rivera-Pérez J, Welsh MJ, Beaudet AL, Bradley A (1993) A severe phenotype in mice with a duplication of exon 3 in the cystic fibrosis locus. Hum Mol Genet 2:1561-1569. https://doi.org/10.1093/hmg/2.10.1561

Oppy CC, Jebeli L, Kuba M, Oates CV, Strugnell R, Edgington-Mitchell LE, Valvano MA, Hartland EL, Newton HJ, Scott NE (2019) Loss of $O$-linked protein glycosylation in Burkholderia cenocepacia impairs biofilm formation and siderophore activity and alters transcriptional regulators. mSphere 4:e0660-19. https:// doi.org/10.1128/mSphere.00660-19

O'Sullivan LA, Weightman AJ, Jones TH, Marchbank AM, Tiedje JM, Mahenthiralingam E (2007) Identifying the genetic basis of ecologically and biotechnologically useful functions of the bacterium Burkholderia vietnamiensis. Environ Microbiol 9:1017-1034. https://doi.org/10.1111/j.1462-2920.2006.01228.x

Panta PR, Doerrler WT (2021) A Burkholderia thailandensis DedA family membrane protein is required for proton motive force dependent lipid A modification. Front Microbiol 11:618389. https://doi.org/10.3389/fmicb.2020.618389

Papp-Wallace KM, Becka SA, Zeiser ET, Ohuchi N, Mojica MF, Gatta JA, Falleni M, Tosi D, Borghi E, Winkler ML, Wilson BM, LiPuma JJ, Nukaga M, Bonomo RA (2017) Overcoming an extremely drug resistant (XDR) pathogen: avibactam restores susceptibility to ceftazidime for Burkholderia cepacia complex isolates from cystic fibrosis patients. ACS Infect Dis 3:502-511. https://doi.org/10.1021/acsinfecdis.7b00020 
Peeters C, Daenekindt S, Vandamme P (2016) PCR detection of Burkholderia multivorans in water and soil samples. BMC Microbiol 16:1-7. https://doi.org/10.1186/s12866-016-0801-9

Pizzolla A, Hultqvist M, Nilson B, Grimm MJ, Eneljung T, Jonsson IM, Verdrengh M, Kelkka T, Gjertsson I, Segal BH, Holmdahl R (2012) Reactive oxygen species produced by the NADPH oxidase 2 complex in monocytes protect mice from bacterial infections. J Immunol 188:5003-5011. https://doi.org/10.4049/ jimmunol.1103430

Ratcliff R, Evans MJ, Cuthbert AW, MacVinish LJ, Foster D, Anderson JR, Colledge WH (1993) Production of a severe cystic fibrosis mutation in mice by gene targeting. Nat Genet 4:35-41. https://doi.org/10.1038/ng0593-35

Rozmahel R, Wilschanski M, Matin A, Plyte S, Oliver M, Auerbach W, Moore A, Forstner J, Durie P, Nadeau J, Bear C, Tsui LC (1996) Modulation of disease severity in cystic fibrosis transmembrane conductance regulator deficient mice by a secondary genetic factor. Nat Genet 12:280-287. https://doi.org/10. 1038/ng0396-280

Sabet M, Griffith DC (2020) Activity of aerosolized levofloxacin against Burkholderia cepacia in a mouse model of chronic lung infection. Antimicrob Agents Chemother 64:e01988-e2019. https://doi.org/10.1128/AAC.01988-19

Saikh KU, Dankmeyer JL, Zeng X, Ulrich RG, Amemiya K (2019) An increase in intracellular p62/NBR1 and persistence of Burkholderia mallei and B. pseudomallei in infected mice linked to autophagy deficiency. Immun Inflamm Dis 7:7-21. https://doi. org/10.1002/iid3.239

Sass A, Slachmuylders L, Van Acker H, Vandenbussche I, Ostyn L, Bové M, Crabbé A, Chiarelli LR, Buroni S, Van Nieuwerburgh F, Abatih E, Coenye T (2019) Various evolutionary trajectories lead to loss of the tobramycin-potentiating activity of the quorumsensing inhibitor baicalin hydrate in Burkholderia cenocepacia biofilms. Antimicrob Agents Chemother 63:e02092-e2118. https://doi.org/10.1128/AAC.02092-18

Sawana A, Adeolu M, Gupta RS (2014) Molecular signatures and phylogenomic analysis of the genus Burkholderia: proposal for division of this genus into the emended genus Burkholderia containing pathogenic organisms and a new genus Paraburkholderia gen. nov. harboring environmental species. Front Genet 5:429. https://doi.org/10.3389/fgene.2014.00429

Scoffone VC, Chiarelli LR, Makarov V, Brackman G, Israyilova A, Azzalin A, Forneris F, Riabova O, Savina S, Coenye T, Riccardi G, Buroni S (2016) Discovery of new diketopiperazines inhibiting Burkholderia cenocepacia quorum sensing in vitro and in vivo. Sci Rep 6:32487. https://doi.org/10.1038/srep32487

Seed KD, Dennis JJ (2008) Development of Galleria mellonella as an alternative infection model for the Burkholderia cepacia complex. Infect Immun 76:1267-1275. https://doi.org/10.1128/IAI.01249-07

Seynos-García E, Castañeda-Lucio M, Muñoz-Rojas J, López-Pliego L, Villalobos M, Bustillos-Cristales R, Fuentes-Ramírez LE (2019) Loci identification of a N-acyl homoserine lactone type quorum sensing system and a new LysR-type transcriptional regulator associated with antimicrobial activity and swarming in Burkholderia gladioli UAPS07070. Open Life Sci 14:165-178. https://doi.org/10.1515/biol-2019-0019

Shastri S, Spiewak HL, Sofoluwe A, Eidsvaag VA, Asghar AH, Pereira T, Bull EH, Butt AT, Thomas MS (2017) An efficient system for the generation of marked genetic mutants in members of the genus Burkholderia. Plasmid 89:49-56. https://doi.org/10.1016/j. plasmid.2016.11.002

Slinger BL, Deay JJ, Chandler JR, Blackwell HE (2019) Potent modulation of the CepR quorum sensing receptor and virulence in a Burkholderia cepacia complex member using non-native lactone ligands. Sci Rep 9:13449. https://doi.org/10.1038/ s41598-019-49693-x
Snouwaert JN, Brigman KK, Latour AM, Malouf NN, Boucher RC, Smithies O, Koller BH (1992) An animal model for cystic fibrosis made by gene targeting. Science 257:1083-1088. https://doi. org/10.1126/science.257.5073.1083

Sousa SA, Ulrich M, Bragonzi A, Burke M, Worlitzsch D, Leitão JH, Meisner C, Eberl L, Sá-Correia I, Döring G (2007) Virulence of Burkholderia cepacia complex strains in gp91 9 phox-/ mice. Cell Microbiol 9:2817-2825. https://doi.org/10.1111/j.1462-5822. 2007.00998.x

Spadaro F, Scoffone VC, Chiarelli LR, Fumagalli M, Buroni S, Riccardi G, Forneris F (2016) The crystal structure of Burkholderia cenocepacia DfsA provides insights into substrate recognition and quorum sensing fatty acid biosynthesis. Biochemistry 55:3241-3250. https://doi.org/10.1021/acs.biochem.6b00178

Srinon V, Chaiwattanarungruengpaisan S, Korbsrisate S, Stevens JM (2019) Burkholderia pseudomallei $\mathrm{BimC}$ is required for actinbased motility, intracellular survival, and virulence. Front Cell Infect Microbiol 9:63. https://doi.org/10.3389/fcimb.2019.00063

Srisanga K, Suthapot P, Permsirivisarn P, Govitrapong P, Tungpradabkul S, Wongtrakoongate P (2019) Polyphosphate kinase 1 of Burkholderia pseudomallei controls quorum sensing, RpoS and host cell invasion. J Proteomics 194:14-24. https://doi.org/10.1016/j. jprot.2018.12.024

Stöckel S, Meisel S, Elschner M, Melzer F, Rösch P, Popp J (2015) Raman spectroscopic detection and identification of Burkholderia mallei and Burkholderia pseudomallei in feedstuff. Anal Bioanal Chem 407:787-794. https://doi.org/10.1007/ s00216-014-7906-5

Suppiger A, Aguilar C, Eberl L (2016) Evidence for the widespread production of DSF family signal molecules by members of the genus Burkholderia by the aid of novel biosensors. Environ Microbiol Rep 8:38-44. https://doi.org/10.1111/1758-2229. 12348

Tedesco P, Visone M, Parrilli E, Tutino ML, Perrin E, Maida I, Fani R, Ballestriero F, Santos R, Pinilla C, Di Schiavi E, Tegos G, de Pascale D (2015) Investigating the role of the host multidrug resistance associated protein transporter family in Burkholderia cepacia complex pathogenicity using a Caenorhabditis elegans infection model. PLoS One 10:e0142883. https://doi.org/10. 1371/journal.pone.0142883

Trespidi G, Scoffone VC, Barbieri G, Riccardi G, De Rossi E, Buroni S (2020) Molecular characterization of the Burkholderia cenocepaciadcw operon and FtsZ interactors as new targets for novel antimicrobial design. Antibiotics (Basel) 9:841. https://doi.org/ 10.3390/antibiotics9120841

Trottmann F, Franke J, Richter I, Ishida K, Cyrulies M, Dahse HM, Regestein L, Hertweck C (2019) Cyclopropanol warhead in malleicyprol confers virulence of human- and animal-pathogenic Burkholderia species. Angew Chem Int Ed Engl 58:14129_ 14133. https://doi.org/10.1002/anie.201907324

Uehlinger S, Schwager S, Bernier SP, Riedel K, Nguyen DT, Sokol PA, Eberl L (2009) Identification of specific and universal virulence factors in Burkholderia cenocepacia strains by using multiple infection hosts. Infect Immun 77:4102-4110. https://doi.org/10. 1128/IAI.00398-09

van Doorninck JH, French PJ, Verbeek E, Peters RH, Morreau H, Bijman J, Scholte BJ (1995) A mouse model for the cystic fibrosis delta F508 mutation. EMBO J 14:4403-4411. https://doi.org/10. 1002/j.1460-2075.1995.tb00119.x

Vandenbussche I, Sass A, Pinto-Carbó M, Mannweiler O, Eberl L, Coenye T (2020) DNA methylation epigenetically regulates gene expression in Burkholderia cenocepacia and controls biofilm formation, cell aggregation, and motility. mSphere 5:e00455-20. https://doi.org/10.1128/mSphere.00455-20

Vanhoutte B, Cappoen D, Maira BM, Cools F, Torfs E, Coenye T, Martinet W, Caljon G, Maes L, Delputte P, Cos P (2017) 
Optimization and characterization of a murine lung infection model for the evaluation of novel therapeutics against Burkholderia cenocepacia. J Microbiol Methods 139:181-188. https://doi. org/10.1016/j.mimet.2017.06.003

Vergunst AC, Meijer AH, Renshaw SA, O'Callaghan D (2010) Burkholderia cenocepacia creates an intramacrophage replication niche in zebrafish embryos, followed by bacterial dissemination and establishment of systemic infection. Infect Immun 78:14951508. https://doi.org/10.1128/IAI.00743-09

Veselova MA, Romanova YM, Lipasova VA, Koksharova OA, Zaitseva YV, Chernukha MU, Gintsburg AL, Khmel IA (2016) The effect of mutation in the $c l p X$ gene on the synthesis of $\mathrm{N}$-acylhomoserine lactones and other properties of Burkholderia cenocepacia 370. Microbiol Res 186-187:90-98. https://doi.org/10. 1016/j.micres.2016.03.009

Vio SA, García SS, Casajus V, Arango JS, Galar ML, Bernabeu PR, Luna MF. Paraburkholderia, In Beneficial microbes in agro-ecology, Editor(s): N. Amaresan, M. Senthil Kumar, K. Annapurna, Krishna Kumar, A. Sankaranarayanan, Academic Press, 2020, Pages 271-311, ISBN 9780128234143, https://doi. org/10.1016/B978-0-12-823414-3.00015-0

Wagley S, Vanaporn M, Rinchai D, Conejero L, Lertmemongkolchai G, Bancroft GJ, Titball RW (2017) A proteasome inhibitor produced by Burkholderia pseudomallei modulates intracellular growth. Microb Pathog 107:175-180. https://doi.org/10.1016/j.micpath. 2017.03.015

Waldron EJ, Snyder D, Fernandez NL, Sileo E, Inoyama D, Freundlich JS, Waters CM, Cooper VS, Neiditch MB (2019) Structural basis of DSF recognition by its receptor RpfR and its regulatory interaction with the DSF synthase RpfF. PLoS Biol 17:e3000123. https://doi.org/10.1371/journal.pbio.3000123

Wang H, Cisse OH, Bolig T, Drake SK, Chen Y, Strich JR, Youn JH, Okoro U, Rosenberg AZ, Sun J, LiPuma JJ, Suffredini AF, Dekker JP (2020) A phylogeny-informed proteomics approach for species identification within the Burkholderia cepacia complex. J Clin Microbiol 58:e01741-e1820. https://doi.org/10.1128/JCM. 01741-20

Wang K, Li X, Yang C, Song S, Cui C, Zhou X, Deng Y (2021) A LysR family transcriptional regulator modulates Burkholderia cenocepacia biofilm formation and protease production. Appl Environ Microbiol 87:e0020221. https://doi.org/10.1128/AEM.00202-21

Wattal C, Oberoi JK, Goel N, Raveendran R, Khanna S (2017) Matrix-assisted laser desorption ionization time of flight mass spectrometry (MALDI-TOF MS) for rapid identification of micro-organisms in the routine clinical microbiology laboratory. Eur J Clin Microbiol Infect Dis 36:807-812. https://doi.org/10. 1007/s 10096-016-2864-9

Wilke M, Buijs-Offerman RM, Aarbiou J, Colledge WH, Sheppard DN, Touqui L, Bot A, Jorna H, de Jonge HR, Scholte BJ (2011) Mouse models of cystic fibrosis: phenotypic analysis and research applications. J Cyst Fibros 2:S152-S171. https://doi.org/ 10.1016/S1569-1993(11)60020-9

Wong KSK, Dhaliwal S, Bilawka J, Srigley JA, Champagne S, Romney MG, Tilley P, Sadarangani M, Zlosnik JEA, Chilvers MA (2020) Matrix-assisted laser desorption/ionization time-of-flight MS for the accurate identification of Burkholderia cepacia complex and Burkholderia gladioli in the clinical microbiology laboratory. $\mathrm{J}$ Med Microbiol 69:1105-1113. https://doi.org/10.1099/jmm.0. 001223

Wong Y-C, Abd El Ghany M, Ghazzali RNM, Yap SJ, Hoh CC, Pain A, Nathan S (2018) Genetic determinants associated with in vivo survival of Burkholderia cenocepacia in the Caenorhabditis elegans model. Front Microbiol 9:1118. https://doi.org/10. 3389/fmicb.2018.01118

Wong Y-C, Abd El Ghany M, Naeem R, Lee K-W, Tan Y-C, Pain A, Nathan S (2016) Candidate essential genes in Burkholderia cenocepacia J2315 identified by genome-wide TraDIS. Front Microbiol 7:1288. https://doi.org/10.3389/fmicb.2016.01288

Yabuuchi E, Kosako Y, Oyaizu H, Yano I, Hotta H, Hashimoto Y, Ezaki T, Arakawa M (1992) Proposal of Burkholderia gen. nov. and transfer of seven species of the genus Pseudomonas homology group II to the new genus, with the type species Burkholderia cepacia (Palleroni and Holmes 1981) comb. nov. Microbiol Immunol 36:1251-1275. https://doi.org/10.1111/j.1348-0421. 1992.tb02129.x

Yang C, Cui C, Ye Q, Kan J, Fu S, Song S, Huang Y, He F, Zhang LH, Jia Y, Gao YG, Harwood CS, Deng Y (2017) Burkholderia cenocepacia integrates $c i s$-2-dodecenoic acid and cyclic dimeric guanosine monophosphate signals to control virulence. Proc Natl Acad Sci U S A 114:13006-13011. https://doi.org/10.1073/pnas. 1709048114

Zeiher BG, Eichwald E, Zabner J, Smith JJ, Puga AP, McCray PB Jr, Capecchi MR, Welsh MJ, Thomas KR (1995) A mouse model for the delta F508 allele of cystic fibrosis. J Clin Invest 96:20512064. https://doi.org/10.1172/JCI118253

Publisher's note Springer Nature remains neutral with regard to jurisdictional claims in published maps and institutional affiliations. 